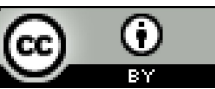

Esta obra está sob o direito de Licença Creative Commons Atribuição 4.0 Internacional.

\title{
O PROFESSOR UNIVERSITÁRIO NA CONTEMPORANEIDADE
}

\author{
Nadson Ribeiro ${ }^{1}$ \\ Luciano Canuto Jacinto ${ }^{2}$ \\ Ione Pereira da Silva ${ }^{3}$ \\ Maria Isabel da Silva Martins ${ }^{4}$ \\ Lucimairy Silva Lemos 5
}

\section{RESUMO}

Nos últimos anos a educação não tem sido prioridade para o Governo. O sucessivo corte de verbas do ensino público ( $\mathrm{R} \$ 3.200 .000$, em menos de 8 anos), a falta de reajuste salarial, o fim da assistência estudantil, a política de privatização tem ocasionado o sucateamento das Universidades Federais. A Lei de Diretrizes e Bases da Educação Nacional (LDB) promulgada em 1996, que passou a priorizar o ensino fundamental, veio a contribuir ainda mais para o descaso do Governo com o ensino Superior, que é visto como privilégio de poucos. Hoje 70\% dos alunos em nível superior estão matriculados em instituições particulares, enquanto apenas $30 \%$ estão em Universidades públicas. Essa porcentagem reflete a lógica capitalista que manobra a educação. Educação é mercadoria, 'tem quem pode pagar'. Essa lógica excludente torna o ensino superior cada vez mais elitizado e vai desobrigando o Estado de oferecer educação de qualidade e para todos, uma vez que tem quem faça esse papel, a um preço bem alto. A produção do conhecimento, hoje, no Ensino Superior tem sido nortea da e definida pelas exigências do mercado e está se distanciando cada vez mais das necessidades da sociedade. Diante dessa situação, é urgente pensar em uma Reforma Universitária que devolva a Universidade seu caráter público, universal e de formação crítica.

Palavras-chave: Educação Superior. Aluno. Brasil. Professor.

\footnotetext{
${ }^{1}$ Graduado em Educação Artística e especialista em Formação para a Docência do Ensino Superior pelo Centro Universitário (CESMAC0.

${ }^{2}$ Mestrando em Ciências da Educação (Absoulute Christian University).

${ }^{3}$ Graduada em Pedagogia pela Universidade Estadual de Alagoas.

${ }^{4}$ Graduada em Enfermagem pela Universidade Federal de Alagoas.

${ }^{5}$ Graduado em Pedagogia pelo Centro Universitário CESMAC.
} 


\section{INTRODUÇÃO}

A Educação Brasileira desde 1930 (e, sobretudo, em 1932, com o Manifesto dos Pioneiros) até 1975 tem passado por diversas modificações. O admirável Manifesto permanece atual nos dias difíceis da educação: a crítica severa contra o legalismo pressuroso sem respaldo científico. Nas recentes reformas da universidade e do ensino de $1^{\circ}$ e $2^{\circ}$ graus, permanece intacta a pressurosidade cartorial contra a pesquisa. Entretanto, no devenir social, é normal a décalage entre os anos de 1932 e 1975, em que se enfatiza a escola numa visão do passado, e conceitua o planejamento numa perspectiva liberal superada. O Manifesto vislumbra a interdisciplinaridade do saber, mas depois do documento se assinala o avanço considerável quanto à conexão entre as diferentes ciências. Entretanto, persiste a dificuldade do método interdisciplinar no ensino. Em virtude da diacronia (o tempo sócio-político, econômico, cultural e educacional), o documento não percebe o conteúdo real da educação permanente. Acentua a administração escolar, mas omite a administração educacional. A escola, como instituição relativamente autônoma (na concepção do Manifesto), estava encaixada na ideologia liberal. Além disso, a sociedade industrial exige, obviamente, macroestruturas. A ideia da totalidade, e das conexões que lhe dão coerência, impõe-se à cultura moderna, transformando, crescentemente, o estilo liberal e individualista num estilo planejado $\mathrm{e}$ societário da ação social. Nesse caso, tornase indispensável a administração educacional, como macroestrutura.

A preocupação com a avaliação no ensino superior é uma questão antiga e presente tema de discussão entre docentes e estudantes após a reforma universitária. $\mathrm{E}$ logo após esta ter ocorrido criou-se o PARU - Programa de Avaliação da Reforma Universitária. Este programa organizado pelo MEC com participação do INEP Instituto Nacional de Pesquisas Educacionais e do Conselho Federal de Educação viria a se constituir um dos primeiros projetos de avaliação nacional. Aos poucos abandonado, o PARU não chegou a ser implementado em sua totalidade.

Como a reforma universitária, ocorrida no país pela Lei n. ${ }^{\circ} 5.540 / 68$ provocou a transformação radical na estrutura e funcionamento do ensino superior nacional, havia a necessidade de se diagnosticar os efeitos e consequências dessa reforma. Ainda na década de 70, mais especificamente a partir de 1975, verificamse algumas tentativas de elaboração de uma avaliação com o objetivo de "mensurar" os 
impactos ou a produtividade resultante dessa mudança.

Vale lembrar que a educação na década de 70 era predominantemente tecnicista. A preocupação com a eficiência e eficácia do ensino era a tônica, visto que educação nos "países subdesenvolvidos" e depois qualificados como "em desenvolvimento" era concebida acima de tudo como um "alto investimento econômico" e que, portanto deveria produzir retorno. Pode-se dizer que a tendência pedagógica predominante era influenciada pela teoria do capital humano. Nessa vertente, avaliação significava acima de tudo o controle dos insumos (inputs), e dos produtos (outputs) da educação.

$\mathrm{Na}$ década seguinte, após a reabertura política e com a conquista de "direitos democráticos", como por exemplo, a eleição para reitores das universidades, a avaliação passa a ser pauta de administrações de universidades comprometidas com a construção de uma gestão democrática e com a autonomia universitária. Algumas universidades organizaram comissões de professores com o compromisso de pensar a avaliação. A ausência de uma cultura de avaliação sistematizada, a forma pouco prática como essas avaliações ocorriam, e principalmente, a não repercussão dessas avaliações na política de gestão das universidades, podem ter sido os fatores que fizeram com que essas avaliações não se consolidassem.

A análise da avaliação institucional não pode ser feita apenas do ponto de vista técnico, não pode ser feita sem que tenhamos a clareza sobre qual orientação está posta, em termos de política educacional. Do ponto de vista governamental as propostas de avaliação na maioria das vezes estiveram orientadas pela lógica empresarial, visando o retorno do investimento educacional, ressaltando a produtividade, os resultados quantitativamente mensuráveis, e consequentemente nunca conseguiram estabelecer um padrão unitário de qualidade para o ensino, a pesquisa e a extensão.

A discussão sobre avaliação, embora para alguns não pareça, há muito tem estado presente no interior das universidades públicas, no movimento docente, no cotidiano da prática docente acadêmica, nesse sentido a questão não é nova. Embora alguns cheguem até a considerar que os professores universitários não querem enfrentar esta questão, ela é antiga no meio acadêmico, porque tem estado presente em sucessivos governos, e tem sido ponto de pauta nos Congressos Nacionais e CONADS - Conselho do Sindicato Nacional dos Docentes das Instituições de Ensino Superior, do 
movimento docente da categoria. Ao mesmo tempo, pode-se afirmar que esta é uma questão nova, uma vez que até hoje não se conseguiu, de fato, implantar uma avaliação verdadeiramente institucional, se criar uma cultura de avaliação no nosso dia a dia. Recolocar esta questão discuti-la, nunca foi tão necessário, tão urgente e tão atual.

A reflexão sobre a avaliação nos remete a necessidade de contextualizar a educação e mais especificamente a questão da avaliação no âmbito das universidades públicas brasileiras. A preocupação com a

\section{METODOLOGIA}

O presente trabalho é uma revisão de literatura, não sistemática, de caráter descritivo e natureza qualitativa. Após análise de livros obtidos em bibliotecas físicas e virtuais foram desenvolvidas cinco

\section{RESULTADOS E DISCUSSÕES}

\section{A estrutura e o funcionamento do ensino superior no Brasil atual}

$\mathrm{Na}$ Constituição Federal (em seu art. $\left.5^{\circ}\right)$ fica, igualmente, estabelecido que a Educação - um direito de todos e dever do Estado e da família - será promovida e incentivada, com a colaboração da sociedade, visando ao pleno desenvolvimento da pessoa, ao seu preparo para o exercício da cidadania e à sua avaliação no ensino superior já era uma questão presente e tema de discussão entre docentes e estudantes após a reforma universitária. Portanto, convém que façamos uma pequena retrospectiva de alguns fatos do cenário da educação brasileira. E esse é motivo pelo qual se justifica a escolha deste tema: analisar tudo o que ocorreu e vem ocorrendo com as Universidades ao longo do tempo. Analisar o que mudou e o que não; se foi bom ou ruim; o que professores e alunos ganharam e/ ou perderam com o passar dos anos.

categorias temáticas: a estrutura e o funcionamento do ensino superior no Brasil atual; diferenciação de cursos e programas de formação superior; a educação superior a distância no Brasil; o papel do professor e o professor - conflitos da contradição.

qualificação para o trabalho. O ensino, por sua vez, deverá ser ministrado com base nos princípios de igualdade de condições para o acesso e permanência na escola, com coexistência de instituições públicas e privadas; garantindo a gratuidade e gestão democrática do ensino público (art. 206, inciso I a VII). (NEVES, 2008, p.38)

Os sistemas de ensino, no Brasil, são organizados em regime de colaboração entre a União, os Estados e o Distrito 
Federal (art. 211, § 1 a 4): à União, cabe a organização do sistema de ensino federal e dos Territórios, financiando as instituições públicas federais e exercendo, em matéria educacional, função redistributiva e supletiva, de forma a garantir equalização de oportunidades educacionais e padrão mínimo de qualidade mediante assistência técnica e financeira aos Estados, ao Distrito Federal e aos Municípios; aos Municípios cabe a responsabilidade de atuarem, prioritariamente, no Ensino Fundamental e na Educação Infantil; os Estados e o Distrito Federal atuam principalmente no ensino fundamental e médio, definindo formas de colaboração, de modo a assegurar a universalização do ensino obrigatório. Nos últimos anos, Estados e Municípios passaram a atuar, também, no nível superior. (NEVES, 2008, p.39)

Além dos princípios gerais estabelecidos pela Constituição, o sistema educativo brasileiro foi redefinido pela nova Lei de Diretrizes e Bases Nacional (LDBN), Lei ${ }^{\circ}$ 9.394/96, na qual ficaram estabelecidos os níveis escolares e as modalidades de educação e ensino, bem como suas respectivas finalidades. Fonte: (NEVES, 2008, p.39)

Os níveis escolares dividem-se em: Educação Básica - É composta pela Educação Infantil, Ensino Fundamental e Ensino Médio; e Educação Superior - ministrada em instituições de ensino superior (públicas ou privadas), com variados graus de abrangência ou especialização.

As modalidades de educação e ensino complementam o processo de educação formal por meio de Educação de jovens e adultos, Educação profisssional, Educação especial, Ensino presencial, Ensino semipresencial, Educação à distância e Educação continuada.

A Educação Superior no Brasil abarca, hoje, um sistema complexo e diversificado de instituições públicas e privadas com diferentes tipos de cursos e programas, incluindo vários níveis de ensino, desde a graduação até a pósgraduação lato sensu em várias áreas, e stricto sensu (mestrado e doutorado).

\section{Diferenciação de cursos e programas de formação superior}

Pós-graduação lato sensu:

Cursos de especialização: são oferecidos a candidatos que tenham concluído a graduação, com duração mínima de 360 horas. Têm usualmente um objetivo técnico profissional específico, não abrangendo o campo total do saber na qual se insere.

Cursos sequenciais: destinam-se à obtenção ou atualização de qualificações técnicas, profissionais ou, ainda, acadêmicas ou de horizontes intelectuais 
em campos das ciências, das humanidades e das artes. Esses cursos distinguem-se em:

Cursos sequenciais de formação específica: com destinação coletiva, conduzem a obtenção de diploma. Têm como objetivo assegurar uma formação básica adequada num campo de saber. As disciplinas, nele cursadas, podem ser aproveitadas em cursos de graduação.

Cursos sequenciais de complementação de estudo: destinação coletiva ou individual, dirigidos exclusivamente para egressos ou matriculados em cursos de graduação, conduzindo a obtenção de certificado.

Sequenciais de complementação de estudos com destinação individual: é o próprio candidato quem apresenta sua proposta de sequência de disciplinas a serem cursadas. Caberá às IES, então, avaliarem a coerência e a lógica interna da proposta, bem como a existência de vagas nas disciplinas requeridas.

Sequenciais de complementação de estudos com destinação coletiva: é a instituição que elabora a proposta curricular do curso, bem como a respectiva carga horária e prazo de integralização. Permite que as disciplinas nele cursadas sejam aproveitadas, pelo aluno, no caso de ele se matriculas em um curso de graduação (desde que os currículos das disciplinas sejam equivalentes).
Programas de Extensão: são abertos à comunidade em geral. A extensão é entendida como uma prática acadêmica que interliga a universidade, nas suas atividades de ensino e pesquisa, com as necessidades da população, possibilitando a formação do profissional-cidadão.

Pós-graduação Stricto Sensu:

O mestrado é uma modalidade stricto sensu que se divide em duas categorias: Mestrado Acadêmico e o Profissionalizante, as duas categorias conferem um título de mestre e exige capacitação de concentração e cuja duração mínima é de um ano. Só que o mestrado profissional está totalmente voltado para a área especifica no exercício de sua profissão, enquanto o mestrado acadêmico é mais abrangente porque busca aprofundar e ampliar o conhecimento no âmbito da pesquisa cientifica.

O doutorado é uma formação acadêmica stricto sensu, concedida nos estabelecimentos de ensino superior que confere a pessoa um título de Doutor, cuja finalidade é certificar a capacidade do indivíduo nas pesquisas de uma determinada área do conhecimento.

A Educação Superior a Distância no Brasil

O primeiro curso de graduação a distância criado foi o de Pedagogia de $1^{\mathrm{a}}$ a $4^{\mathrm{a}}$ série da Universidade Federal de Mato 
Grosso, em caráter experimental, a partir de 1995 para professores em serviço da rede pública estadual e municipal.

A educação a distância foi identificada num primeiro momento com o ensino por correspondência, porque era baseada em textos e exercícios transportados pelo correio. A segunda geração da educação a distância na universidade começou na década de 80, com o uso da televisão e do vídeo cassete para os telecursos profissionalizantes e formadores de estudantes do ensino médio e fundamental. A terceira fase que promete ser uma revolução no ensino brasileiro, começou no final da década de 90 . Há cinco anos, apenas 200 mil pessoas no país estudavam pelo método da educação à distância. Hoje com a Internet, são cerca de 1,2 milhões de estudantes. (NEVES et al., 2008)

A partir de 1998, observa-se um crescente envolvimento de Instituições de Ensino Superior com cursos de educação à distância. As solicitações de autorização ao Ministério de Educação foram, em sua grande maioria, 80\%, para cursos de graduação de formação de professores, principalmente de Pedagogia e Normal Superior.

As instituições superiores de ensino estão finalmente começando a atuar de forma clara e decidida em educação à distância. O avanço da Internet está trazendo grandes mudanças para a educação presencial, ao introduzir momentos e técnicas de educação à distância. E a educação a distância começa a aproximarse da presencial, a sair do nicho em que se encontrava. (NEVES et al., 2008)

A educação presencial domina praticamente todas as modalidades de ensino superior. São aproximadamente 30 cursos de graduação em funcionamento ou aprovados. 81 Instituições de Ensino Superior desenvolvem algum tipo de cursos à distância, a maioria de extensão, de curta duração. Aumentam os cursos de especialização.

O panorama atual é muito dinâmico. As empresas estão buscando processos de capacitação contínua, fazendo parcerias com as melhores universidades. As Secretarias de Educação também procuram estas instituições superiores para convênios e cursos.

Segundo Costas (2002) há cursos de curta e de longa duração, há cursos para poucos alunos (- 30 alunos) e cursos com mais de 15 mil alunos. Há cursos totalmente on-line, virtuais e outros impressos, que utilizam só correio.

Em termos institucionais, a oferta de cursos superiores a distância poderia ser classificada dentro das seguintes três grandes tendências: 
Instituições isoladas: são Universidades e Faculdades de Ensino Superior que já atuam na educação presencial e agora oferecem cursos à distância. Em geral começam com cursos de extensão, depois com cursos de especialização e atualmente estão organizando cursos de graduação.

Associações e Consórcios: são Instituições de Ensino Superior brasileiras que unem seus esforços para oferecer cursos à distância em vários níveis. Há associações que são pontuais, temporárias, para um curso ou projeto específico. E há associações que pretendem ser duradouras, para juntar os melhores professores, cursos e recursos das instituições.

Instituições

exclusivamente

virtuais: instituições criadas exclusivamente para oferecer cursos à distância, operando no momento apenas em cursos de extensão. Temos portais ou sites que funcionam como um campus virtual, em geral oferecendo cursos de extensão.

\section{O papel do professor}

Sabe- se que ensinar não é transmitir dogmaticamente conhecimentos, mas dirigir e incentivar com habilidade e método, a atividade espontânea e criadora do educando. Nessas condições, o ensino compreende todas as operações e processos que favorecem e estimulam o curso vivo e dinâmico da aprendizagem.

Segundo Marcetto (2001, p.49) existem alguns princípios importantes a serem considerados por todos os que se preocupam com a aprendizagem do aluno, que são:

A aprendizagem deve envolver o aluno, ter um significado com o seu contexto, para que realmente aconteça;

A aprendizagem é pessoal, pois envolve mudanças individuais;

Objetivos reais devem ser estabelecidos para que a aprendizagem possa ser significativa para os alunos;

Como a aprendizagem se faz um processo contínuo, ela precisa ser acompanhada de feedback visando fornecer os dados para eventuais correções;

Como a aprendizagem envolve todos os elementos do sistema, o bom relacionamento interpessoal é fundamental.

No entanto, na realidade das escolas, quando se procura decodificar o significado de ensinar, as ideias definem o professor como agente principal e responsável pelo ensino, sendo as atividades centralizadas em suas qualidades e habilidades. Aprender também relaciona um único agente principal e responsável, o aprendiz (aluno), estando às atividades centradas em suas capacidades, possibilidades e condições para que aprenda. 
Diante deste contexto, percebemos que o perfil do educador não mudou muito. $\mathrm{Na}$ verdade, poucos são os que fogem ao conceito de educação bancária, ou seja, o saber não passa de uma doação dos que se julgam sábios aos que julgam que nada sabem, cabendo então aos sábios dar, entregar, transmitir o seu grande saber.

Portanto, a educação se torna um simples ato de depositar, onde os educandos são os depositários e o educador o depositante.

Infelizmente a prática pedagógica docente presa este processo mecânico, aula expositiva, para ser copiada e decorada. Depois é restituída na prova e, finalmente, na "cola" é copiada com a máxima perfeição. Portanto aula, prova e cola são sinônimos no espírito da coisa.

Em contraposição a esta prática Freire (1996, p.98) afirma que, "ninguém educa ninguém, ninguém educa a si mesmo, os homens se educam entre si, mediatizados pelo mundo", ou seja, a educação problematizadora é como prática de liberdade; exige de seus personagens uma nova concepção de comportamento. Ambos são educadores e educandos, aprendendo e ensinando em conjunto, mediatizados pelo mundo.

A construção da educação libertadora tem que enfrentar o problema de selecionar o conteúdo que constituirá o conhecimento a ser processado na escola de modo democrático, competente, culturalmente significativo e comprometido com a transformação social e que, ao mesmo tempo, tenha por eixo os interesses e necessidades da maioria dos alunos.

Aprender é apenas meio. A qualidade da formação básica é o fator modernizante mais eficaz da sociedade e da economia. Muito embora a valorização da educação no sistema produtivo moderno não mude a essência do capitalismo, introduz, na sombra de vantagem para o capital, oportunidades pertinentes para o trabalhador, que incluem parâmetros menos drásticos de exploração da mão de obra, sem falar no suporte para a cidadania do trabalhador.

A educação é componente substancial de qualquer política de desenvolvimento, não só como bem em si e como mais eficaz instrumentação de cidadania, mas igualmente como o primeiro investimento tecnológico.

Segundo essa linha, o educador passa a ser o problematizador, que desafia os educando que são agora investigadores críticos, permeados por constantes diálogos, pois a educação como prática de liberdade deve negar o conceito de isolamento e abstração do ser humano, assim como tornar o mundo uma presença constante em seu diálogo. 
Sendo esta uma das características principais da Educação Bancária, definida e caracterizada por Paulo Freire quando nos diz: que denominava o modelo tradicional de prática pedagógica de "educação bancária”, pois entendia que ela visava à mera transmissão passiva de conteúdo do professor, assumido como aquele que supostamente tudo sabe, para o aluno, que era assumido como aquele que nada sabe. Era como se o professor fosse preenchendo com seu saber a cabeça vazia de seus alunos; depositava conteúdos, como alguém deposita dinheiro num banco. O professor seria um mero narrador, nessa concepção de educação.

\section{O Professor - Conflitos da contradição}

O que falar da prática avaliativa que acontece em nossas escolas? Por que o discurso do professor é inovador enquanto sua prática é conservadora? O que dá origem a esta contradição? Velhos mitos impregnam a prática avaliativa que desde sempre esteve a serviço do autoritarismo dos professores.

Hoffmann (2001) acredita que a contradição entre o discurso e a prática de alguns educadores e principalmente a ação classificatória e autoritária exercida pela maioria, encontra explicação na concepção de avaliação do educador, reflexo de sua história como aluno e professor. Existe a vontade de fazer diferente, porém não se sabe como fazer. Assim, o primeiro passo seria tomar consciência destas influências para que não se venha a reproduzir o que se contesta no discurso: o autoritarismo e a arbitrariedade.

A educação escolar é uma intervenção intencional no processo histórico da produção concreta da existência humana. Portanto, o sentido radical e último da escola e de sua prática é a percussão social, o impacto e o significado concreto desta intervenção. No momento histórico de mudanças profundas, em que a dimensão efetivamente humana de todos e de cada uma das pessoas está sendo chamada ao palco da história, a intervenção educativa escolar se torna mais decisiva e fundamental.

No que diz respeito à democratização da educação, requer que se discuta autonomia e gestão democrática como construtores indissociáveis e intrínsecos do processo de educação emancipadora. Portanto, só faz sentido discuti-los a partir e em função do projeto político-pedagógico existente numa unidade escolar.

Para tanto, o referido procura enunciar alguns princípios e significados sobre autonomia e gestão democrática como balizadores das discussões no âmbito 
das unidades escolares da rede pública estadual. (PARENTE, 2007. p.149)

Os educadores constroem seu jeito de ensinar no cotidiano da sala de aula, e é a partir daí que deve se conduzir uma reflexão sobre sua prática e a construção de uma identidade profissional. Neste contexto, o educador também pode construir e produzir uma teoria, a partir do momento que se transforma em investigador, ou seja, quando se debruça sobre sua prática, fundamentando-a e iluminando-a sob a luz da teoria.

O professor Freire (2006, p.111) nos mostra que ensinar não é transmitir conhecimentos, mas criar as possibilidades para a produção do saber. Ensinar exige muitos fatores, estes são citados de forma clara e conclusiva. Uma das primeiras exigências é a rigorosidade metódica, o Educador norteando-se por este saber deve reforçar a capacidade crítica do educando auxiliando-o a tornar-se criador, investigador, inquieto, rigorosamente curioso, humilde e persistente; $\mathrm{O}$ facilitador deve ensinar os conteúdos mais também ensinar a pensar certo.

Os conhecimentos contidos nos livros são muito importantes, porém ter apenas estes saberes e não estar antenado com a realidade do seu mundo, sabendo das necessidades e ocorrências do seu país, sua cidade, seu bairro e ainda de sua rua é pensar errado. Ele ainda afirma que o professor precisa pensar certo para só então ensinar a pensar certo. Ensinar exige pesquisa, o autor deixa claro neste estudo que, ensino sem pesquisa não é ensino, pesquisa e ensino estão intrinsecamente relacionados. Ensinar exige respeito aos saberes do educando, o facilitador segundo sugestão do autor deve discutir com os alunos a realidade concreta a que se deve associar a disciplina, estabelecendo uma familiaridade entre os saberes curriculares fundamentais e a experiência social de cada um dos aprendizes. (Freire, 2006, p.112)

Ensinar exige criticidade, ter uma postura de curiosidade e inquietação indagadora e discernidora. Ensinar exige ética, e estética, a prática educativa tem a obrigação moral de ser um testemunho rigoroso de decência e de pureza, o professor não pode estar longe ou fora da ética por ser portador do caráter formador, o ensino dos conteúdos não pode estar alheio à formação moral do educando. Ensinar exige também a corporeificação das palavras pelo exemplo, quem pensa certo tem consciência que palavras nada valem se não forem seguidas do exemplo. Pensar certo é fazer certo. O clima de quem, pensa certo deve ser o de quem busca a generosidade. Ensinar exige risco, aceitação do novo e rejeição a qualquer forma de discriminação. O ser é ofendido e para ele é 
restrito o direito à democracia, quando acontece qualquer uma das práticas discriminatórias.

Ao longo dos tempos, teoria e prática aparecem em lados opostos, como se fossem dissociados, e o "estado" desta relação é objeto de críticas e controvérsias onde se acentua exatamente sua ausência.

Retomando a discutida relação teoria/prática, assumimos que ela não pode ser vista como uma correlação mecânica; tratamos de compreender a relação que há entre estes dois mundos que compõem o humano. A construção do pedagógico é feita por homens que sonham, sentem, projetam, mas vivem num mundo histórico, de relações concretas, onde a teoria constrói. Logo, privilegiar o ensino teórico, baseando a formação de professores somente na literatura, sem a ponte com o cotidiano, significa colocar a prática a um plano sem relevância para a compreensão do que significa o ato docente (NOGARO, 2002, p.276).

O planejamento escolar é de suma importância, pois é um processo de racionalização, organização e coordenação da ação docente, articulando a atividade escolar e a problemática do contexto social.

A escola, os professores e os alunos são integrantes da dinâmica das relações sociais; tudo o que acontece no meio escolar está atravessado por influências econômicas, políticas e culturais que caracterizam a sociedade de classes. Isso significa que os elementos do planejamento escolar tais como: objetivos, conteúdos e métodos estão recheados de implicações sociais, têm um significado genuinamente político. Por essa razão, o planejamento é uma atividade de reflexão acerca das nossas opções e ações; se não pensarmos detidamente sobre o rumo que devemos dar ao nosso trabalho, ficaremos entregues aos rumos estabelecidos pelos interesses dominantes na sociedade.

A ação de planejar é uma atividade consciente de previsão das ações docentes, fundamentadas em opções políticopedagógicas, e tendo como referência permanente situações didáticas concretas (isto é, a problemática social, econômica, política e cultural que envolve a escola, os professores, os alunos, os pais, a comunidade, que interagem no processo de ensino).

O planejamento escolar tem, assim, as seguintes funções:

a) Explicitar princípios, diretrizes e procedimentos de trabalho docente que assegurem a articulação entre as tarefas da escola e as exigências do contexto social e do processo de participação democrática.

b) Expressar os vínculos entre o posicionamento filosófico, 
político-pedagógico e profissional; as ações efetivas que o professor irá realizar em sala de aula, através de objetivos, conteúdos, métodos e formas organizativas de ensino.

c) Assegurar a racionalização, organização e coordenação do trabalho docente, de modo que a previsão das ações docentes possibilite ao professor a realização de um ensino de qualidade e evite a improvisação e rotina.

d) Prever objetivos, conteúdos e métodos a partir da consideração das exigências propostas pela realidade social, do nível de preparo e das condições socioculturais e individuais dos alunos.

e) Assegurar a unidade e a coerência do trabalho docente, uma vez que torna possível interrelacionar, num plano, os elementos que compõem o processo de ensino: os objetivos (para que ensinar), os conteúdos (o que ensinar), os alunos e suas

\section{CONCLUSÃO}

Sendo assim, é importante valorizar o professor com salários justos e dignos e oferecer condições de trabalho, além de possibilidades (a quem ensinar), os métodos e técnicas (como ensinar) e a avaliação, que está intimamente relacionada aos demais.

f) Atualizar o conteúdo do plano sempre que é revisto, aperfeiçoando-o em relação aos progressos feitos no campo de conhecimentos, adequando-os às condições de aprendizagem dos alunos, aos métodos, técnicas $\mathrm{e}$ recursos de ensino que vão sendo incorporados na experiência cotidiana.

g) Facilitar a preparação das aulas: selecionar o material didático em tempo hábil, saber que tarefas professor e alunos devem executar replanejar o trabalho frente a novas situações que aparecem no decorrer das aulas.

Para que os planos sejam efetivamente instrumentos para a ação, devem ser como um guia de orientação que devem apresentar ordem sequencial, objetividade, coerência, flexibilidade.

reorganizar o tempo e os espaços escolares, tornando a escola um local agradável, onde o estudante goste de ir e permanecer por estar motivada em participar de seu próprio processo formativo. Entende-se então que a 
formação do professor não é feita de maneira distinta, primeiro a teórica e depois a experiência prática, mas sim no diálogo da prática com a teoria. E, neste diálogo, é necessário problematizar a experiência prática, buscando alternativas, avaliando o cotidiano escolar e as próprias ações. É assim que o professor aprende se aperfeiçoa e principalmente se descobre um investigador, um prático reflexivo, produtor de conhecimentos e um artista, capaz de criar suas próprias ações.

Face ao exposto, conclui-se que o trabalho do professor universitário não se restringe à simples transmissão de informações e conhecimentos, mas estendese à necessidade de apresentá-los sob a forma de problemas que deverão ser resolvidos, situando-os num determinado contexto e abordando-os em uma perspectiva interdisciplinar. A escassez de financiamento e recursos pedagógicos, bem como as turmas, muitas vezes, superlotadas comprova uma profunda deteriorização das condições de trabalho dos docentes universitários. Devem ser mantidos no

\section{REFERÊNCIAS}

FAURE, E. Aprender a Ser. São Paulo: Livraria Bertrand, 2006

FREIRE, P. Pedagogia da autonomia. Rio de Janeiro: Paz e Terra, 1996. ensino superior somente os bons profissionais e a estes devem ser oferecidas boas condições de trabalho e remuneração. Este estudo objetivou demonstrar a importância da motivação de alunos e da valorização do profissional de docência, sendo tais práticas, a única maneira eficaz de aperfeiçoar o processo de ensinoaprendizagem.

Pela análise das literaturas consultadas nesta monografia, conclui-se que a má qualidade do ensino superior, em sua maior parte resulta da falta de envolvimento dos professores, gerando o desinteresse dos alunos. A fim de que se consiga chegar a uma solução para este problema, deve-se, primeiramente, priorizar a motivação dos professores, levando-os a envolver-se com o processo educativo. Toda atividade que é desempenhada com prazer surte efeitos positivos. Somente motivando primeiro os professores, é que se conseguirá o envolvimento dos alunos e, consequentemente, a melhoria do ensino universitário.

HOFFMANN, J. Avaliar para promover: as retas do caminho. Porto Alegre:

Mediação: 2001

\section{MASETTO, M. T. Docência na} universidade. Campinas: Papirus, 2002. 
NEVES, C. E. B. A estrutura e o funcionamento do ensino superior no Brasil. In: Soares, M. S. A. (Coord.). A Educação Superior no Brasil. Porto Alegre: Coordenação de Aperfeiçoamento de Pessoal de Nível Superior. 2008. p. 222 271. Disponível em:

$<$ http://flacso.redelivre.org.br/files/2013/03 /1109.pdf $>$. Acesso em: 16 de jan. 2020.

NOGARO, A. Teoria e saberes docentes: a formação de professores na Escola Normal e no Curso de Pedagogia. Erechim:

EdiFAPES, 2002
PAQUAY, L; WAGNER, M.C. Competências profissionais privilegiadas nos estágios e na videoformação. In:

ALTET, M; CHARLIER, E; PAQUAY, L. Formando Professores Profissionais. Quais estratégias? Quais competências?2. ed. Porto Alegre, 2001. p. 135 - 158.

PERRENOUD, P. O trabalho sobre o Habitus na formação de professores: análise das práticas e tomadas de consciência. In: ALTET, M; CHARLIER, E; PAQUAY, L. Formando Professores Profissionais. Quais estratégias? Quais competências?2. ed. Porto Alegre, 2001. p. $161-183$. 